\title{
NADMSYP 1994
}

\section{ORAL PRESENTATIONS}

\section{0-14 August '94, Portland, OR}

\section{Primary Care Opportunities for Rural Paramedics}

\author{
*David R. Johnson, MD, FACEP, Scott Dull, MD, \\ Ron Burnham, NREMT-P \\ New Mexico Emergency Medical Services Academy, Department \\ of Emergency Medicine, University of New Mexico School of \\ Medicine, Albuquerque, New Mexico
}

Hypothesis: Rural paramedics often are called upon to perform primary care functions for which they are not specifically trained.

Methods: Paramedics in a rural New Mexico town with no other health-care providers were asked to fill out a form on all patient encounters regardless of how they originated. The form captured patient age, gender, how encounter occurred, nature of the call, and whether transport to a hospital occurred. A consecutive sample of patient encounters was collected from 01 August 1993 through September 30, 1993. Each form then was reviewed by the director of a statewide paramedic training program to determine if the nature of the patient encounter was covered in traditional paramedic training. The $t$-test was used for statistical analysis.

Results: Of a total of 219 encounters, 23 patients were transported $(10.5 \%)$. Transported patients were older than nontransported patients: $47.8 \pm 23.8$ years vs. 35.6 \pm 22.9 years $(p=0.017)$. Of the nontransported patients, $47.4 \%$ required minor wound care, $31.1 \%$ required primary care referral, and $8.2 \%$ sought patient education. Patients who walked into the fire station accounted for $69.4 \%$ of all encounters. Traditional paramedic curriculum was judged to be inadequate to deal with $20.1 \%$ of all encounters.

Conclusions: In some rural areas, most patient encounters may involve primary care which, by default, is delivered by prehospital providers. A traditional paramedic curriculum may need to be expanded to deal with such encounters.

*Denotes the author who will make presentation

\section{Cardiac Arrest in the Nursing Home: An Exercise in Futility?}

\author{
R. Swor, DO, R. Jackson, MD, D. Barth-Jones, MS, \\ $R$. Benkendorf, MD, E.J. Rivera, $M D$ \\ Department of Emergency Medicine, William Beaumont \\ Hospital, Royal Oak, Michigan
}

Objective: To compare EMS system characteristics and outcome between nursing home $(\mathrm{NH})$ patients and outof-hospital cardiac arrest (OHCA) patients who arrest in a residence (home).

Design: Retrospective study reviewing OHCA from July 1989 to December 1993. Variables abstracted included: age, witnessed arrest (WITN), response intervals, automatic external defibrillator (AED) use, and initial electrocardiographic rhythms. Outcomes were hospital admission (AD) and discharge (DC). Pearson's Chi-square was used for analysis.

Setting: Suburban EMS system.

Subjects: Patients $>19$ years with arrest of presumed cardiac cause, with locations at home or at a NH.

Results: The records for 2,358 total cardiac arrests were complete for analysis; $189 \mathrm{NH}$ and 2,169 home cases. Groups were not different for \% WITN, or BLS and ALS response intervals. $\mathrm{NH}$ patients were more likely to receive CPR on collapse, were older, and were less likely to have an AED used than were victims of home arrests. Initial rhythm and survival to $A D$ and $D C$ were:

$\begin{array}{lccccccc} & \mathrm{n} & \begin{array}{c}\text { Avg age } \\ \text { yr }\end{array} & \begin{array}{c}\text { VF } \\ \%\end{array} & \begin{array}{c}\text { Asystole } \\ \%\end{array} & \begin{array}{c}\text { CPR } \\ \%\end{array} & \begin{array}{c}\text { AD } \\ \%\end{array} & \begin{array}{l}\text { DC } \\ \%\end{array} \\ \mathrm{NH} & 189 & 73.2 & 18.5 & 49.2 & 32.8 & 10.6 & 0.0 \\ \text { Home } & 2,169 & 67.6 & 41.2 & 35.0 & 17.0 & 18.1 & 5.4 \\ \text { p-value } & & 0.001 & 0.001 & 0.04 & 0.014 & 0.10 & \end{array}$

Conclusion: During this 4.5-year study period, no NH patient survived. Initial rhythm is an important factor in this finding. The \%CPR is increased, EMS response is not different, and these factors should not adversely contribute to NH survival 